\title{
Normal Grief Versus Pathological Grief: Should we Prescribe Pharmacological Treatment?
}

\section{Omar Walid Muquebil Ali Al Shaban Rodríguez ${ }^{1 *}$, Sara Solares Rodríguez ${ }^{2}$ and Celia Rodríguez Turiel1}

1Psychiatry Service, San Agustín University Hospital, Spain

2Department of Psychology Ciaño, Mentalia Langreo, Spain

\section{Letter to Editor}

Volume 3 Issue 2

Received Date: June 10, 2019

Published Date: July 08, 2019

DOI: $10.23880 / \mathrm{mhrij}-16000128$

*Correspondence author: Omar Walid Muquebil Ali Al Shaban Rodríguez, Psychiatry

Service, San Agustín University Hospital, Camino de Heros, 4. CP 33401, Avilés, Asturias, Spain, Tel: +34679225311;

Email: muquebilrodriguez@gmail.com

\section{Letter to Editor}

Complicated grief (CG) has been conceptualized as one in which the process intensifies to such an extreme that the person feels overwhelmed, resorting to maladaptive behaviors, or remaining without moving towards resolution in the grieving process, with intrusive symptoms in form of memories or fantasies, intense accesses of emotions and unbearable longings, avoidance of places and people that remember the deceased and inability to adapt [1].

The proposed diagnostic criteria for CG include:

- Stress due to the emotional separation that implies death. Present, every day or in an accused way 3 of the following 4 symptoms: intrusive thoughts (that enter the mind without control) about the deceased; longing for the deceased (memory of his absence with great and deep sadness); search behaviors of the deceased, even knowing that he is dead; feelings of loneliness as a result of death.

- Stress for the psychic trauma that death entails. Present, every day or in an accused manner, and as a result of death, 4 of the following 8 symptoms: lack of goals and/or having the feeling that everything is useless with respect to the future; subjective feeling of coldness, indifference and/or absence of emotional response; difficulty in accepting the reality of death; feel that life is empty and/or that it has no meaning; feel that a part of oneself has died; assume symptoms and/or harmful behaviors of the deceased, or related to him; excessive irritability, bitterness and/or anger in relation to death; have altered the way of seeing or interpreting the world.

- The duration of the symptoms mentioned must be at least 6 months.

- The disorder causes a significant deterioration of social life, work or other significant activities of the life of the grieving person. The goals of grief psychotherapy include mainly learning in the management of very intense emotions. A specific psychotherapeutic approach that was called "treatment of complicated grief" was compared to a more classic interpersonal therapy in a 2005 work, offering better and faster response rates [2]. Regarding the pharmacological treatment, the birth of the DSM 5 brought the controversy about the medicalization of normal mourning (uncomplicated or non-pathological) [3].

We conducted a review of the literature on the evidence about the effectiveness of pharmacological treatment in the grieving process, complicated or not, obtaining the following remarkable results: In 1991, a work using nortriptyline found improvement in all areas of associated depression to the duel, although not in the intensity of the duel [4]. As early as 1999 and continuing with nortriptyline versus placebo, nortriptyline was superior to placebo in improving the symptoms of major depressive disorder associated with grief, with better results through the simultaneous use of psychotherapy 


\section{Mental Health \& Human Resilience International Journal}

[5]. A year before (1998), a comparison between paroxetine and nortriptyline offered positive and similar results between both molecules, although the authors chose to recommend paroxetine, among other reasons because of its better tolerability and greater safety in case of overdose [6]. A 2001 study concluded that the use of bupropion sustained release decreased the intensity of grief symptoms (in addition to improving depressive symptoms), even the authors questioning the idea maintained in the DSM-IV that the symptoms of grief do not complicated should not receive pharmacological treatment [7]. An interesting study of 2007 found efficacy in the global improvement of CG symptoms using escitalopram in monotherapy, without the use of concomitant psychotherapy [8]. More recent is a work that concludes that the aforementioned psychotherapeutic approach, known in English as "treatment of complicated grief", would be the treatment of choice for CG, and the addition of citalopram optimizes the treatment of concomitant depressive symptoms [9]. In 2012, a review of the literature found tricyclic antidepressants effective, although more on depressive symptoms than on the specific symptoms of grief. This same study concluded that selective serotonin reuptake inhibitors (SSRIs) were effective in both depressive and specific symptoms of grief, and psychotherapeutic interventions would be more effective with the simultaneous use of SSRIs [10]. Interesting the conclusion obtained by Bryant RA, in which the fact of introducing specific diagnoses for the answers of CG would minimize the possibility of carrying out an inadequate treatment, consequence of an erroneous diagnosis, positioning therefore against the critical voices with the DSM 5 in his way of conceptualizing the CG [3].

\section{References}

1. Horowitz MJ, Siegel B, Holen A, Bonano GA, Milbrath C, et al. (1997) Diagnostic criteria for complicated grief disorder. Am J Psychiatry 154(7): 904-910.
2. Shear K, Frank E, Houck PR, Reynolds CF (2005) Treatment of complicated grief: A randomized controlled trial. JAMA 293(21): 2601-2608.

3. Bryant RA (2013) Is pathological grief lasting more than 12 months grief or depression? Curr Opin Psychiatry 26(1): 41-46.

4. Pasternak RE, Reynolds CF III, Schlernitzauer M, Hoch CC, Buysse DJ, et al. (1991) Acute open-trial nortriptyline therapy of bereavement-related depression in late life. J Clin Psych 52(7): 307-310.

5. Reynolds CF, Miller MD, Pasternak RE, Frank E, Perel JM, et al. (1999) Treatment of bereavement-related major depressive episodes in later life: a controlled study of acute and continuation treatment with nortriptyline and interpersonal psychotherapy. Am J Psychiatry 156(2): 202-208.

6. Zygmont M, Prigerson HG, Houck PR, Miller MD, Shear MK, et al. (1998) A post hoc comparison of paroxetine and nortriptyline for symptoms of traumatic grief. J Clin Psyc 59(5): 241-245.

7. Zisook S, Shuchter SR, Pedrelli P, Sable J, Deaciuc SC (2001) Bupropion sustained release for bereavement: results of an open trial. J Clin Psych 62(4): 227-330.

8. Simon NM, Thompson EH, Pollack MH, Shear MK (2007) Complicated grief: a case series using escitalopram. Am J Psychiatry 164(11): 1760-1761.

9. Shear MK, Reynolds CF, Simon NM, Zisook S, Wang Y, et al. (2016) Optimizing treatment of complicated grief: A randomized clinical trial. JAMA Intern Med 73(7): 685-694.

10. Bui E, Nadal-Vicens M, Simon NM (2012) Pharmacological approaches to the treatment of complicated grief: rationale and a brief review of the literature. Dialogues Clin Neurosci 14(2): 149-157.
Omar Walid Muquebil Ali Al Shaban Rodríguez, et al. Normal Grief Versus Pathological Grief: Should we Prescribe Pharmacological Treatment?. Ment Health Hum Resilience Int J 2019, 3(2): 000128. 